\title{
La vacunación contra la viruela en la provincia de San Luis Potosí tras la expedición de Balmis: 1805-1821
}

\author{
Ana Irisarri Aguirre \\ Universidad Autónoma de San Luis Potosí \\ airisarriaguirre@yahoo.es
}

\begin{abstract}
Resumen
La expedición de Balmis zarpó de La Coruña (España) en 1804 con la misión de llevar la vacuna contra la viruela a toda la población de la América hispana. Su intención era vacunar al mayor número de niños posible y, sobre todo, preparar a las autoridades de cada región para que continuara10n con la labor e hicieran llegar el nuevo remedio a toda la población, tanto del campo como de la ciudad. Este artículo tratará de mostrar - a través del análisis de los informes de las distintas autoridades de la región - hasta qué punto se puso en práctica este proyecto, a qué autoridades implicó, qué problemas tuvo que enfrentar, cuál fue la reacción de la población y qué resultados consiguió desde 1805 - año en que la expedición llegó a San Luis Potosí- hasta 1821, cuando terminó la época virreinal.
\end{abstract}

Palabras clave: viruelas, vacuna, siglo XIX, Nueva España, expedición de Balmis, historia de la ciencia.

\begin{abstract}
The expedition of Balmis set sail from La Coruña (Spain) in 1804 with the mission of taking the vaccine against smallpox to the inhabitants of Hispanic America. Its goal was to vaccinate as many children as possible, and, specially, to prepare the authorities of different regions to continue with this job and to bring the new cure to urban as well as to rural populations. The article will show to what extent this project was put into practice, how people reacted about it, which authorities were involved, what problems it had to face, and what the results were since 1805-year when the expedition came to San Luis Potosíuntil 1821 -when the viceregal period ended.
\end{abstract}

Key words: Smallpox, vaccine, $19^{\text {th }}$ century, New Spain, Expedition of Balmis, history of science. 


\section{FRONTERAS}

de la fistoria

Uno de los resultados más sobresalientes del Siglo de las Luces y que mejor expresa la mentalidad ilustrada propia de esta centuria es el descubrimiento de la vacuna contra la viruela y los esfuerzos que se realizaron para generalizarla. Aun a riesgo de parecer exagerados, podemos decir que en esta experiencia se puede observar lo mejor del movimiento ilustrado y de sus intentos por mejorar la calidad de vida de la población ${ }^{1}$. Desde luego, en este proyecto no sólo intervinieron las razones humanitarias, sino también los intereses políticos y económicos: la mortalidad causada por cada una de las epidemias cíclicas que sacudían a la población significaban una fuerte pérdida demográfica que tenía un grave efecto en la situación económica y política de las distintas regiones ${ }^{2}$. Por otro lado, en una época en la que todos los Estados occidentales trataban de mostrar el desarrollo de su nación y su superioridad sobre el resto de los Estados ilustrados, el progreso en la vacunación era una importante victoria.

En el caso de los virreinatos americanos, el análisis de los estudios por erradicar la viruela tiene un significado especial porque fue una epidemia que causó una gran mortandad entre la población americana desde la llegada de los españoles y porque en 1804 el gobierno español organizó una expedición que, partiendo desde España, debía extender la recién descubierta vacuna por todos los territorios dominados por el gobierno español ${ }^{3}$.

La expedición de la vacuna o expedición de Balmis ha generado una abundante bibliografía. Desde la segunda mitad del siglo XIX y hasta nuestros días se han publicado numerosos artículos en revistas médicas y varios libros sobre el tema ${ }^{4}$. La mayoría de estas obras se han centrado en la propia expedición: sus

\footnotetext{
${ }^{1}$ El rey Carlos IV, en la real orden del 6 de junio de 1803, que daba luz verde a la expedición de Balmis para extender la vacuna por todos los territorios de la América hispana, indicó que la vacuna debía ser totalmente gratuita. En una carta escrita en 1806, Jenner, el descubridor de la vacuna, elogió el mérito humanitario de la expedición (Páez 301).

${ }^{2}$ Watts relaciona los primeros esfuerzos por generalizar la vacuna con la necesidad de vidas jóvenes para participar en las guerras napoleónicas que se dieron durante estos primeros años del siglo XIX en Europa: "Un supuesto tácito era que los jóvenes así salvados brindarían la carne de cañón necesaria para la próxima guerra [...]" (168).

${ }^{3}$ Véase Guerra y para México (Bustamante 68-69).

${ }^{4}$ La bibliografía existente sobre la expedición de Balmis es muy numerosa. Ya en el siglo XIX se escribieron varias obras sobre el recorrido realizado por los integrantes de esta expedición y sobre la historia de la vacuna contra la viruela en general. Cronológicamente se pueden destacar las siguientes obras: Ovieta (1860), Moreno Caballero (1885), Castillo y Romper (1912), Albiñana y Sanz (1919), Gimeno Caballas (1923), Mariscal (1923), Clavijo y Clavijo (1935), Regli Fernández y Palma Alonso (1936), Rumeu de Armas (1940), Cook (1949), Díaz de Yraola
} 
objetivos, preparación, personas que la integraron, rutas que cubrieron, actividades que realizaron, personas a las que vacunaron, dificultades que tuvieron que afrontar, etc. En algunos casos, los trabajos han abarcado todo el recorrido de la expedición, y en otros se han centrado en alguno de los virreinatos o capitanías generales por las que pasaron los expedicionarios. Sin embargo, los historiadores apenas se han interesado por las "consecuencias" de la misión en los territorios visitados; es decir, no se ha analizado hasta qué punto la expedición no fue algo efímero, sino que la labor fue continuada por las distintas autoridades provinciales y locales de manera regular.

Ésta es la laguna que trata de llenar este trabajo y, para ello nos vamos a centrar en la provincia de San Luis Potosí (el actual Estado de San Luis Potosí, en México). Al tratarse de una región de frontera, también podremos conocer hasta qué punto llegaron a los territorios periféricos los avances producidos por la Ilustración.

El periodo estudiado abarca desde 1805, cuando el médico Gutiérrez, uno de los ayudantes de Balmis, llegó a la capital potosina, hasta 1821, cuando termina oficialmente el periodo de la Colonia. Poner los límites cronológicos a un estudio histórico siempre es muy delicado, pero el hecho de que la generalización de la vacuna fuera una decisión real y totalmente dirigida desde el Estado (como veremos, intervino todo el escalafón de autoridades) nos indujo a pensar que con el fin del virreinato se cierra una primera etapa en la lucha contra la viruela. A pesar de todo, debemos ser conscientes de que estos mismos esfuerzos $u$ otros similares continuaron por parte de los distintos gobiernos independientes en las décadas siguientes.

Las fuentes usadas para realizar este trabajo se componen, fundamentalmente, de reales cédulas y ordenanzas sobre el tema $y$, sobre todo, de la correspondencia que mantuvieron el virrey, el intendente, los miembros del Cabildo civil de la ciudad de San Luis Potosí, los subdelegados, los curas párrocos, los médicos y los cirujanos sobre el progreso de la vacunación. Estas cartas, que en ocasiones son auténticos informes, nos muestran los resultados obtenidos, los problemas que tuvieron que enfrentar, la visión que tenían sobre la enfermedad y su tratamiento - tanto las autoridades como la élite regional y

(1956), Ruiz Moreno (1956), Rico Avello (1958), Archila (1969), Smith “The Real” (1974), Nieto Antúnez (1981), Ballester Añón (1986), Calleja Folguera (1988), Santamaría (1990), Rigau-Pérez "La difusión" (1992), Olagüe de Ros (1995), Balaguer Perigüell (1996), Ramírez Martín La mayor (1999), Barona Vilar (2001), Ramírez Martín La salud (2002) y Ramírez Martín et al. (2004). 


\section{FRONTERAS}

de la historia

el pueblo llano-, los escasos recursos económicos de que disponían para llevar a cabo su cometido y las deficiencias del sistema sanitario en la mayor parte de los pueblos de la intendencia.

La mayor parte de la documentación se encuentra en el Archivo Histórico de San Luis Potosí (AHSLP) aunque también hemos consultados algunos legajos del Archivo General de la Nación (AGN) en la ciudad de México y de la Biblioteca Rafael Montejano y Aguinaga, del Colegio de San Luis Potosí (BRMA).

Comenzaremos haciendo un recuento de las principales epidemias que sufrió la Nueva España durante su etapa colonial y el impacto que éstas produjeron en la población. Posteriormente, nos centraremos en la proceso de vacunación, repasando la labor de Balmis y sus acompañantes tanto en los años de la expedición (1804-1805), como en 1810, cuando él volvió a América con el objetivo de comprobar los avances realizados; finalmente, fijaremos nuestra atención en los esfuerzos de las autoridades potosinas por poner en práctica las indicaciones de Balmis, los logros que se consiguieron y las dificultades que enfrentaron.

\section{San Luis Potosí durante los últimos años del virreinato}

El territorio de la antigua provincia de San Luis Potosí se corresponde con el del actual estado del mismo nombre en México. Aunque geográficamente se encontraba localizado en el centro del virreinato, se trata de una región que a comienzos del siglo XIX podía considerarse periférica por sus características demográficas, económicas y culturales y por el escaso control que ejercía el Estado sobre ella, aunque esto último estaba cambiando durante esos años (Irisarri).

La provincia potosina se creó territorialmente en 1786. Como resultado de la reorganización territorial y administrativa que llevó a cabo el gobierno español en ese año, el virreinato de Nueva España fue dividido en doce intendencias (O'Gormann 15-25). La de San Luis Potosí fue creada ese mismo año al unirse las alcaldías de Guadalcázar, Villa de Valles, Salinas del Peñón Blanco, Venado y Charcas; San Luis Potosí quedó como capital de la provincia y de la intendencia. A su vez, la nueva provincia fue dividida en ocho subdelegaciones o partidos (la capital, Santa María del Río, Rioverde, Villa de Valles, Guadalcázar, Salinas del Peñón Blanco, Venado y Charcas). Cada uno de ellos, 
salvo el de la capital, estaba gobernado por un subdelegado que dependía del intendente, quien, a su vez, respondía al virrey ${ }^{5}$.

La población total de la provincia rondaba los 200 mil habitantes, pero sólo la ciudad capital, la Congregación de los Ranchos y el Valle de San Francisco alcanzaban los 15 mil habitantes. El resto del territorio (incluyendo las cabeceras de los partidos) tenía una población mucho menor y diseminada en ranchos, haciendas y comunidades rurales más o menos aisladas.

La base de la economía potosina era la agricultura, la ganadería y, especialmente, la minería, pero esta última se encontraba en franco declive debido a la decadencia de los centros mineros tradicionales, como el Cerro de San Pedro o Guadalcázar (Monroy, Breve).

\section{El azote de la viruela durante la época virreinal y los primeros intentos por erradicarla}

La llegada de los españoles a América trajo consigo una serie de agentes patógenos y epidemias desconocidas en el Nuevo Mundo y, por tanto, especialmente peligrosas, ya que la población no estaba inmunizada frente a ellas. Este hecho diezmó drásticamente la población americana, contribuyendo al dominio español no sólo por las numerosas pérdidas de vidas que ocasionó, sino también por la confusión y miedo que creó entre la población afectada (Bustamante 68-69, 72) .

El primer brote de viruela que se dio en México coincidió con la caída de Tenochtitlan, en 1521; la epidemia permaneció endémica durante 94 años y se extendió por la mayor parte de Nueva España. Desde ese momento y hasta el final de la Colonia se dio de forma recurrente hasta en 15 ocasiones: 1615-1616,

\footnotetext{
${ }^{5}$ El partido de San Luis no tuvo un subdelegado, sino que era gobernado directamente por el intendente.

${ }^{6}$ La mayor parte de las crónicas escritas durante los años de la Conquista coinciden en señalar que la viruela llegó a América por medio de un esclavo africano que estaba al mando de Pánfilo de Narváez, quien, paradójicamente, había zarpado desde Cuba con la misión de detener la expedición de Cortés al continente y llevarlo de vuelta a la isla. Entre estas crónicas podemos destacar a Sahagún (80). Es muy significativo que los indígenas tomaran las primeras epidemias de viruela como nueva referencia en el calendario: "Llamaron los indios a este mal huizahuatl [...] Desde la cual, como cosa muy señalada, contaban después en sus años" (López de Gómara $150)$.
} 


\section{FRONTERAS}

de la historia

Vol.12 / 2007

$1653,1663,1667,1678,1687,1707,1711,1734,1748,1761,1778-1780,1790$, 1795 y $1797-1798^{7}$.

Como se puede apreciar, durante el siglo XVIII la viruela también fue endémica y se produjeron nuevos brotes cada diez o 15 años, tiempo suficiente para que hubiera población nueva: niños nacidos desde la última epidemia o personas que se habían trasladado de otros lugares donde no había habido viruela en los años previos. No podemos olvidar que la gente que había sobrevivido a la enfermedad quedaba ya inmunizada (Hopkins 8). La documentación nos muestra que las epidemias de 1790 a 1795 apenas afectaron a la provincia de San Luis Potosí, pero no ocurrió lo mismo en la de 1797-1798: los informes de los subdelegados afirman que fueron afectadas unas 28.500 personas, de las cuales murió casi el $33 \%{ }^{8}$.

El primer remedio para frenar la viruela fue la inoculación: esta técnica consistía en inyectar el virus de una persona infectada a una sana con el fin de provocarle un brote de la enfermedad mucho más leve que la natural y, así, dejarla inmune. Esta práctica nació en Asia y África - concretamente se desarrolló en algunas partes de China, Persia, Arabia y Egipto- y en el siglo XVIII, un médico griego, E. Timón, apoyado por la esposa del embajador británico en Estambul, Mary Wortley Montagu, comenzó a inocular en Europa con el fluido obtenido en Turquía (Miller; Moulin y Chauvin).

El problema de este método era que en ocasiones provocaba una reacción tan violenta que la persona inoculada moría ${ }^{9}$. Además, si el paciente no era aislado convenientemente, podía contagiar la enfermedad a otras personas, provocando una epidemia. Como resultado de todo esto, una gran parte de la población, entre los que se incluyen muchos políticos y autoridades sanitarias, se manifestó

\footnotetext{
${ }^{7}$ Numerosas crónicas hablan sobre estas epidemias. Las más significativas están recogidas en las obras de Bustamante (67-92) y Gibson (448-51).

${ }^{8}$ Estos datos se refieren a seis de los ochos partidos de la provincia (Villa de Valles, Rioverde, Santa María del Río, Salinas del Peñón Blanco, Guadalcázar y Venado) porque, desafortunadamente, no ha sido posible encontrar las cifras de los otros dos (BRMA, SLP 41, 1799). Véase también Izaguirre Torres.

${ }^{9}$ De acuerdo con estudios recientes, la mortalidad provocada por la inoculación fue del $1 \%$, mientras que la enfermedad contagiada de una "forma natural" mató entre el $25 \%$ y el $30 \%$ de los afectados (Hopkins 6-7 y Rigau-Pérez "La introducción”).
} 
en contra de esta práctica a la que consideraban poco efectiva y, sobre todo, muy peligrosa ${ }^{10}$.

A pesar de estas reticencias, la inoculación fue recomendada y se puso en práctica en varios lugares del mundo occidental, incluidas diferentes regiones de México, durante las epidemias de 1778-1780, 1797 y 1798. Los informes disponibles no aportan cifras muy fiables, pero algunos estudios recientes nos revelan que en 1798 murió en la capital del virreinato el 3,5\% de la población inoculada y el 18,5\% de los enfermos no inoculados (Rodríguez de Romo 1-17; Swann 154-169).

Junto con la capital, la ciudad de Guanajuato fue uno de los lugares donde las autoridades estuvieron más interesadas en poner en práctica el nuevo remedio contra la enfermedad: el trabajo de Thompsom nos dice que allí se inoculó al $78 \%$ de los niños y que de ellos murieron entre el $1 \%$ y el $3 \%$. Por el contrario, entre los 3.000 niños que contrajeron la viruela por los medios habituales, murió alrededor del 20\% (Thompson 438).

En San Luis Potosí la población inoculada durante estos años fue mucho menor: en la capital solo fueron 101 personas de las que murieron dos, entre los enfermos no inoculados fallecieron 9.000 (Izaguirre 32). Las cifras de los distritos rurales son las siguientes:

\footnotetext{
${ }^{10}$ Un ejemplo de la controversia sobre los pros y contras del tratamiento es la publicación de Gorraiz Beaumonte.
} 
Tabla 1

Número de personas inoculadas e infectadas en 1798

\begin{tabular}{|l|c|c|c|c|}
\hline \multicolumn{1}{|c|}{ Partido } & $\begin{array}{c}\text { Niños } \\
\text { inoculados }\end{array}$ & $\begin{array}{c}\text { Niños } \\
\text { inoculados que } \\
\text { murieron }\end{array}$ & $\begin{array}{c}\text { Personas } \\
\text { infectadas de } \\
\text { “forma natural”" }\end{array}$ & $\begin{array}{c}\text { Personas que } \\
\text { murieron infectadas } \\
\text { de “forma natural" }\end{array}$ \\
\hline Guadalcázar & 30 & 1 & 2.691 & 880 \\
\hline Venado & 50 & 1 & 2.231 & 948 \\
\hline Río Verde & 16 & 0 & 4.603 & 2.246 \\
\hline Peñón Blanco & 5 & 0 & 1.102 & 33 \\
\hline Valles & 0 & 0 & 7.595 & 860 \\
\hline Santa María & 0 & 0 & 4.450 & \\
\hline
\end{tabular}

Fuente: AHESLP, I 1792-1795, exp. 4.

Además de la inoculación, el otro remedio que podía ser usado para luchar contra la viruela fue la vacunación. Este procedimiento fue descubierto en las Islas Británicas por el médico Jenner, quien realizó una serie de experimentos con un nuevo fluido siguiendo la experiencia de sus pacientes de una zona ganadera en Inglaterra. Se dio cuenta de que las mujeres que ordeñaban las vacas y se infectaban con las secreciones de las pústulas que les salían a los animales en las ubres quedaban inmunes a la viruela.

Los resultados de estos experimentos fueron publicados por el propio Jenner en 1798, y a pesar de las críticas y de la incomprensión de una buena parte de sus colegas, se realizó la primera campaña de vacunación, incluyendo a Nueva York como primera ciudad americana donde se puso en práctica el descubrimiento ${ }^{11}$. Los buenos resultados de la vacuna acabaron con parte de las reticencias, y el método se fue haciendo cada vez más universal. El medico francés Moreau de la Sarthe escribió el Traité historique et pratique de la vaccine (Tratado histórico y práctico de la vacuna) describiendo el origen de la vacuna y los resultados de los experimentos de Jenner (Baxby).

${ }^{11}$ El título del ensayo fue: "An Inquiry into the Causes and Effects of the Variolae Vaccinea, a Disease Discovered in Some of the Western Countries of England, Particularly Gloucestershire, and Known by the Name of Cow Pox". 
En España, el médico Francisco Xavier de Balmis tradujo el tratado de Sarthe al español, y la Corona le confió la dirección de una expedición que debía llevar la vacuna a todos sus dominios españoles y, si los resultados eran satisfactorios, también a las Filipinas (Balmis, Prólogo). En ese tiempo, Balmis ya era un médico con cierto prestigio que tras estudiar en el Hospital Militar de Alicante había tomado parte en varias expediciones militares y había viajado a América en busca de plantas que podrían curar la sífilis y otras enfermedades venéreas ${ }^{12}$.

El proyecto se planteó de una forma extremadamente ambiciosa: debían visitar numerosas ciudades, recorrer grandes distancias y, sobre todo, aleccionar a las distintas autoridades y a los representantes médicos sobre la importancia del proyecto y prepararlos para que fueran ellos los que se encargaran de continuar con la vacunación una vez que la expedición se hubiera marchado. Los expedicionarios sabían que el éxito de la campaña no dependía del número de vacunaciones que realizaran, sino de que las distintas autoridades se encargaran de continuar con la campaña inmunizando a todos los niños que nacieran a partir de ese momento.

La expedición partió desde La Coruña el 30 de noviembre de 1803 con su director, otros tres médicos, dos cirujanos, tres enfermeros, 22 huérfanos del orfanato de La Coruña (con una edad que oscilaba entre los tres y los nueve años) y la directora del orfanato encargada del cuidado de los niños. El único modo de llevar la vacuna al Nuevo Mundo era la técnica del "brazo a brazo": un niño era vacunado cada semana y el pus de sus pústulas era usado para vacunar a otro niño y así sucesivamente hasta el fin del viaje (Bustamante 84; Díaz de Yraola; Ramírez, La salud, La Real; Ruiz Moreno).

\section{La expedición en San Luis Potosí y la fundación de la Junta Central de Vacunación}

El médico Gutiérrez llegó a San Luis Potosí el 5 de enero de 1805 y sólo realizó una sesión de vacunación, ya que el mismo día recibió la orden de volver inmediatamente a México para embarcar en unos días desde Acapulco a las Filipinas y continuar allí con la misión. En esa primera y única sesión fueron vacunados 391 niños y "quedó entendido en el más pronto establecimiento de la Junta Central y Casa de Inoculación" (AHESLP, I 1804.1, exp. 6). Esto último era lo que más interesaba a los miembros de la expedición, ya que por muchas

\footnotetext{
${ }^{12}$ Los resultados de este estudio fueron publicados en España y traducidos a otros idiomas, como el alemán (Balmis Demostración; Balmis y Berenguer).
} 


\section{FRONTERAS}

de la historia

vacunaciones que lograra conseguir, serían insignificantes y, sobre todo, sería algo efímero y pasajero.

Las ordenanzas redactadas por Balmis para las distintas juntas y casas de vacunación (son diez los artículos dedicados a describir la organización y funciones de la Junta, el proceso de vacunación y los requisitos para realizar el procedimiento) (AHESLP, I 1804.1, exp. 6) eran precisas y prácticas: esta institución tenía que encargarse de que fueran vacunados tantos niños como fuera posible de una forma controlada y segura ${ }^{13}$.

De acuerdo con estos artículos, la Junta se encontraba bajo la protección del intendente y el cabildo, y estaba formada por siete u ocho miembros "de los más condecorados y preocupados por el bien público" y de cuatro "profesores". Así pues, se trataba de una medida tomada desde el gobierno y puesta en práctica desde arriba porque el control de la institución queda dividido entre la autoridad metropolitana (el intendente) y la élite criolla de cada región (el cabildo municipal).

Los miembros de la junta debían reunirse cada quince días y no recibirían ningún salario (sólo se pagarían los gastos de papelería y correspondencia a los dos secretarios). Otras funciones de la Junta eran la concesión de licencias a las personas preparadas para practicar la vacunación y la prevención de falsas vacunas o vacunas naturales (las que procedían de una persona que realmente había sufrido viruela y no del pus vacuno) "que tanto daño pueden hacer y que pueden contagiar a quien por descuido o ignorancia no haya aprovechado el preservativo" (AHESLP, I 1804.1, exp. 6).

Por último la junta debía tener socios corresponsales por toda la intendencia, con el objetivo de descubrir si en alguna de las granjas de vacas se encontraba cowpox. Balmis era consciente de que mantener la vacuna únicamente por medio de la cadena de vacunados, es decir, tomando el pus de las pústulas que previamente habían recibido el fluido, era muy difícil, por lo que debían buscarlo en las vacas americanas. Esto era muy complicado, ya que, según afirman estudios como el de Esparza, el verdadero cowpox era un virus propio de roedores silvestres de Europa Occidental y Rusia que sólo infectaban a las vacas e incluso al hombre de forma ocasional ("La introducción"). De todas

${ }^{13}$ Las instrucciones dejadas por Gutiérrez en San Luis Potosí fueron las mismas que dejaron Balmis y sus acompañantes en todas las ciudades que visitaron. La fundación de la Casa de Vacunación en Venezuela fue muy similar a la de San Luis Potosí y tuvo una labor muy fructífera al vacunar a más de cien mil personas de las 980.000 que tenía la población. 
formas, hoy en día todavía no se sabe el origen del fluido vacuno ni se ha podido determinar su relación con el virus de la viruela humana (Moss 2637-71; Páez 304-06).

La vacunación debía realizarse una vez a la semana en una casa dedicada exclusivamente a la vacunación y nunca en hospitales, debido a la pésima opinión que sobre ellos tenía la mayor parte de la población y que podía alejarlos del "nuevo remedio":

[...] no conviniendo de manera alguna el que a los principios se haga depósito de este precioso preservativo en los hospitales, hospicios y casa de expósitos porque, además del desafecto con que comúnmente se miran estos establecimientos que contribuyen a retraer muchos al público y los retrae también el desaseo y constituciones delicadas y enfermizas de los que las habitan, provocan los miedos, no quieren vacunar a sus hijos [...] según lo he visto en todas partes.

Esta idea se mantuvo todavía durante muchos años y a pesar de que en San Luis no se construyó una casa que cumpliera con este objetivo, nunca se vacunó en los hospitales. La documentación consultada nos indica que se reunía a los niños en las plazas de las ciudades o en los pórticos de las iglesias; preferían inocular a los niños al aire libre antes que en un hospital u hospicio. A la semana de ser vacunados los niños debían regresar con el médico para que éste comprobara su estado y si se habían presentado o no granos. Los estatutos también contemplaban la posibilidad de pagar una cantidad de dinero por vacunarse a los niños que fuesen "pobres de solemnidad".

La Junta Central de Vacunación de San Luis Potosí celebró su primera sesión el 21 de enero de 1805. A ella asistieron distintas personalidades tanto del ayuntamiento como del ámbito militar, dos médicos y dos cirujanos que serían los encargados de realizar la vacunación: José Camaño, Antonio Corvera, Pedro Barrenechea y Francisco Guardiola ${ }^{14}$. El puesto de tesorero recayó en el ministro de Real Hacienda de las Cajas Reales de San Luis, y el de secretario, en el alcalde de la Mesta, Pedro García (AHESLP, I 1804-1, exp. 6).

\footnotetext{
${ }^{14}$ Convocatoria por parte del teniente letrado José Ignacio Vélez para la celebración de la primera junta sobre la conservación y aplicación del fluido vacuno, San Luis Potosí, 21 de enero de 1805. Las personas convocadas fueron: los regidores Juan de Gorriño y Juan Antonio Vildosola, Cristóbal Corbalán (tesorero), el alcalde de la Mesta, Pedro García (secretario), el capitán Toribio de la Cortina, los bachilleres José Camaño y Antonio Corbera, los señores José Antonio Otaegui e Ignacio de Oria y los cirujanos Pedro Barrenechea y Francisco Guardiola (AHESLP, I 1804-1, exp. 6).
} 


\section{FRONTERAS}

de la historia

Todo parece indicar que esta Junta sólo funcionó durante ese primer año, ya que no volvió a aparecer en el resto de la documentación. A partir de 1806 no hay ningún indicio de que la Junta se volviera a reunir, y toda la documentación relativa a los progresos o problemas que presenta la vacunación, tanto en la capital de la intendencia como en las distintas subdelegaciones, está firmada por el intendente o por el teniente letrado.

\section{Las vacunaciones en la intendencia de San Luis Potosí}

Al mismo tiempo que se constituía la Junta de Vacunación comenzaron las primeras operaciones. Los médicos trabajaron en sus propias casas: entre enero y marzo aplicaron el fluido a 1.248 personas trabajando cada diez días. A pesar de que no tenemos más información sobre la labor de esta Junta durante los meses siguientes, Pedro García informó en 1810 que durante el tiempo que él estuvo como secretario de la Junta se vacunaron más de diez mil niños de la capital y los barrios de Tlaxcalilla, Santiago, Tequisquiapan y La Santísima Trinidad. No tenemos ningún documento que avale esta afirmación de Pedro García, aunque él remite a "Como constan apuntados de mi letra en un cuaderno que debe parar en esa intendencia y seguí cuando se me confirió el encargo de secretario de la Junta Central de aquella ciudad" (AHESLP, I 18101811.3, exp. 13).

El número que nos da García parece exagerado, ya que en agosto de 1806 fue el médico militar, Alejandro García Arboleya, quien realizó distintas vacunaciones durante su estancia en la ciudad. Concretamente vacunó a 153 niños en el centro de San Luis, a 250 en el barrio de Tlaxcalilla, a 201 en el de Santiago, a 120 en los de Santísima Trinidad, San Juan Evangelista y Tequisquiapan, y a otros 120 en el de San Sebastián (AHESLP, I 1804.1, exp. 6). Parece extraño que tuviera que hacer las vacunaciones un médico que estaba de paso si apenas el año anterior las autoridades locales habían sido capaces de vacunar a más de diez mil personas. Además, el total de la población infantil de los barrios y su capital no llegaba a esta cifra: en 1819 apenas alcanzaban los cuatro mil ${ }^{15}$.

\footnotetext{
15 Se está utilizando el censo de 1819 porque es la estadística más cercana que divide a la población por edades, y nos interesa saber cuántos eran los menores de siete años, ya que eran quienes no habían enfermado durante el último brote $\mathrm{y}$, por tanto, no estaban inmunizados. Además, el total de población era muy parecido en 1805 y 1819, por lo cual las edades de población no debieron cambiar mucho en este breve lapso (Monroy, Pueblos 25-50). En este censo falta la población del centro de la capital, la ciudad española, pero su número no doblaba al de todos sus barrios juntos.
} 
La documentación también nos indica que estas primeras iniciativas no tuvieron continuidad y que no hubo vacunaciones sistemáticas, sino que fueron puntuales: cuando se conseguía el fluido, cuando había profesionales preparados para realizar las operaciones y cuando contaban con el dinero necesario. Efectivamente, y como veremos más adelante, ni las autoridades de la intendencia, ni ninguna iniciativa particular pudieron garantizar la existencia de estos tres requisitos fundamentales para la generalización de la vacuna de manera constante; por tanto, el gran objetivo de la expedición no se pudo conseguir durante estos años.

El número de vacunados en los distintos partidos fue el siguiente: Santa María de Río 7.000; Ríoverde, unas 850 personas más otras 500 en las que "no llegó a fructificar" (AHESLP, I 1810-1811.3, exp. 13); en Valles hubo un primer intento en la capital de la subdelegación, pero apenas prendió en dos personas, posteriormente se hizo otro intento en Valle del Maíz, donde se vacunó a más de 300 de los 525 niños que residían en la ciudad y de allí se extendió a San Nicolás de los Montes, Villa de Valles, Aquismón y Tancahuitz. donde hubo que detenerse por las lluvias torrenciales; en Charcas, concretamente en la localidad de Real de Catorce, se vacunó a 500 niños (AHESLP, I 1810-1811.3, exp. 6 y 13). Por el contrario, en las subdelegaciones de Guadalcázar, Venado y Salinas no se consiguió ningún resultado (AHESLP, I 1810-1811.3, exp. 6, 13 y 15). Salinas fue el único caso en el que no se hizo ningún intento.

En 1810, volvió a Nueva España Francisco Xabier de Balmis con el fin de comprobar los progresos que se habían realizado en la generalización de la vacuna y tratar de solucionar los problemas que se hubieran presentado. Con este motivo se volvió a imprimir el Tratado traducido por él y que debía ser repartido por todo el territorio a partir de los subdelegados. A pesar de todos estos esfuerzos, no hay indicios de más vacunaciones hasta 1814. En ese momento, debido al peligro inminente de una nueva epidemia (desde Puebla había pasado a México y desde allí a Querétaro), se hizo un nuevo esfuerzo. En la capital vacunaron el médico Altamirano con fluido traído de Querétaro, el cirujano Vicente Carrano en el hospital de San Juan de Dios, y el maestro barbero Blas Azpilicueta en su propia casa (AHESLP, I 1814.4, exp. 4 y 1816.1, exp. 3). Las vacunaciones se prolongaron durante los meses desde septiembre de 1814 hasta enero de 1815; Altamirano "inoculó"16 , según su informe, a más

\footnotetext{
${ }^{16}$ Inocular es la palabra que utiliza Altamirano. El hecho de que use esta palabra en lugar de vacunar nos muestra cómo muchas personas utilizaban la misma expresión para nombrar dos acciones muy distintas y, sobre todo, cómo esto pudo influir en el hecho de que la población
} 


\section{FRONTERAS}

de la historia

Vol.12 / 2007

de 600 niños, mientras que Blas Azpilicueta, lo practicó en unos 300 (AHESLP, I 1815.2, exp. 8).

Durante los años 1815 y 1816 el virrey mandó fluido, al menos en cuatro ocasiones: una en 1815 y otras tres en enero, abril y junio de 1816 , pero ninguna de ellas tuvo éxito. Desde finales de ese año y a lo largo de 1817 y 1818 la intendencia y el ayuntamiento potosinos, a instancias del virrey, trataron de buscar el fluido en ciudades cercanas como Querétaro o Zacatecas, pero ellos tampoco tenían existencias. Todo esto hizo que la siguiente vacunación no se produjera hasta septiembre de 1819 , año en que la capital del virreinato volvió a conseguir vacuna y la envió a las distintas provincias. En la capital se volvió a emitir un bando público convocando a la población a vacunarse en casa de Blas de Azpilicueta, y el intendente envió aviso a los distintos partidos y poblaciones cercanas a la población para que mandaran a varios niños con algún responsable a recoger el fluido (AHESLP, I 1819.1, exp. 10) ${ }^{17}$. Desde septiembre y hasta diciembre continuaron las vacunaciones; aunque no nos han quedado datos de cuantas personas se beneficiaron de ellas, sí sabemos que para finales de año otra vez se habían quedado sin el pus necesario.

Es muy difícil saber el porcentaje de niños vacunados en cada uno de los partidos porque los censos están incompletos, porque no suelen incluir el número total de niños existentes y porque los informes no siempre son fiables debido a que, como vimos, las autoridades tienden a exagerar las cifras. Nosotros hemos tomado el censo de 1819 porque es el único que divide a la población en grupos de edad y, por tanto, nos muestra cuántos niños hay menores de siete o 16 años (dependiendo de la fecha de vacunación) que son los que nos interesan porque todavía no son inmunes ${ }^{18}$. En cualquier caso, este censo tampoco es completo porque no incluye la población de los partidos de Charcas, Guadalcázar y Rioverde ni los del centro urbano de la ciudad (sí están las cifras de los barrios o pueblos de indios) ${ }^{19}$. Con todas estas salvedades, las

temiera a este nuevo remedio por creer que se trataba de la inoculación, práctica que, como hemos visto, era mucho más peligrosa.

${ }^{17}$ Entre los distintos partidos y poblaciones que mandaron niños en busca del fluido están: Santa María del Río, Salinas del Peñol Blanco, Rioverde, Guadalcázar, Valles, Tancanhuitz, Mexquitic, Santísima Trinidad, San Sebastián, Tlaxcalilla, Santiago, Tequisquiapan, San Juan y Guadalupe.

${ }^{18}$ La población total era muy similar en 1805 y 1819 así que el número de niños también debió de ser similar (Monroy, Pueblos 25-50; AHESLP, I 1819.1, exp.10 [relativo a la vacuna]).

${ }^{19}$ La ciudad de San Luis Potosí estaba formada por un centro urbano en el que vivían los criollos y mestizos y siete barrios o pueblos de indios que rodeaban este núcleo citadino (Montejano y Aguinaga). 
cifras aproximadas de los partidos sobre los que tenemos información se presentan en la Tabla 2.

Tabla 2

Número de niños vacunados entre 1805 y 1815

\begin{tabular}{|c|c|c|}
\hline Lugar y año & Niños vacunados & $\begin{array}{l}\text { Total de niños menores } \\
\text { de siete años }\end{array}$ \\
\hline Capital de San Luis Potosí (enero 1805) & 391 & --- \\
\hline Capital (enero a marzo 1805) & 1.248 & --- \\
\hline Capital (agosto 1806) & 153 & --- \\
\hline Capital (1814-1815) & 900 & --- \\
\hline 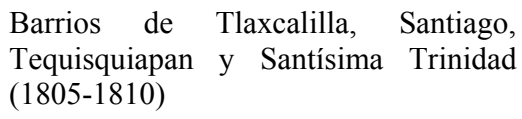 & 10.000 & 1.616 \\
\hline Tlaxcalilla (agosto 1806) & 250 & 799 \\
\hline Santiago (agosto 1806) & 201 & 658 \\
\hline $\begin{array}{l}\text { Trinidad, San Juan y Tequisquiapan } \\
\text { (agosto 1806) }\end{array}$ & 180 & 338 \\
\hline San Sebastián (agosto 1806) & 120 & 391 \\
\hline $\begin{array}{l}\text { Santa María del Río, Valle de San } \\
\text { Francisco y Tierra Nueva (1810-1811) }\end{array}$ & 7.000 & 5.590 \\
\hline Rioverde (1810-1811) & 1,350 & --- \\
\hline Valles (1810-1811) & 2 & 601 \\
\hline Maíz (1810-1811) & 300 & 525 \\
\hline Real del Catorce (1810-1811) & 500 & --- \\
\hline
\end{tabular}

Fuente: AHESLP, I 1819.1, exp.10; Monroy, Pueblos 25-50 y Montejano y Aguiñaga ${ }^{20}$.

\footnotetext{
${ }^{20}$ Además de las vacunaciones de estos años debemos añadir las que se hicieron en 1819 , de las cuales no tenemos cifras exactas.
} 


\section{FRONTERAS}

de la historia

Como se puede apreciar, la guerra de la Independencia no hizo que se redujeran los intentos por extender la vacuna. Una situación similar se produjo en Guanajuato, donde a lo largo de todos estos años se continuó con la campaña, y en otras circunscripciones que también estaban luchando por la independencia, como Venezuela (Esparza y Colmenares 111-12; Thompson 447).

\section{Los esfuerzos de las autoridades y los principales problemas para la generalización de la vacuna}

Los problemas a los que tuvieron que enfrentarse los responsables de la vacunación fueron principalmente cuatro: la dificultad técnica para conservar y trasladar el fluido vacuno a las distintas poblaciones, la falta de recursos económicos dedicados al proyecto, la escasez de profesionales preparados para realizar la vacunación y el miedo de la población a la vacuna, a la que llamaban "enfermedad voluntaria". Es muy difícil saber cuál de estos fue el problema más determinante porque la mayor parte de las veces se daban todos juntos; es decir, a la falta de fluido en condiciones, se unía las dificultades para pagar el viaje, contar con niños que portaran la vacuna, disponer de facultativos preparados para realizar la inoculación y, finalmente, convencer a la gente de que la vacuna no era una "enfermedad voluntaria", sino un eficaz remedio -el único disponible - contra la epidemia. De todas formas, es cierto que si no tenían el producto para vacunar, todo lo demás no tenía demasiada importancia.

El llamado "fluido vacuno" con el que se realizaban las vacunaciones se obtenía de los granos que habían salido a los niños recientemente vacunados; a pesar de que se intentó tomarlo directamente de las vacas, en San Luis esto nunca se consiguió $^{21}$. La conservación del fluido por este medio era muy complicada y evitó que se pudiera realizar una vacunación regular y continuada. La capital de la intendencia debía esperar a que le llegara el fluido de México o de alguna otra ciudad que lo hubiera conseguido, y las poblaciones del interior de la jurisdicción debían trasladar a dos o tres niños con un responsable hasta San Luis con el fin de que fueran inoculados, confiar en que la vacuna tuviera éxito y extraer pus de sus granos para poder vacunar al resto de niños. Esto implicaba

\footnotetext{
${ }^{21}$ A pesar de que Balmis y sus acompañantes insistieron en la necesidad de revisar en las haciendas ganaderas si las vacas mostraban el fluido y no obstante los esfuerzos de las autoridades potosinas por cumplirlo (como se dijo anteriormente, éste era una de los puntos dispuestos en las instrucciones que el director de la Expedición dejó en cada ciudad y una de las obligaciones de la Junta Central de Vacunación), no se llegó a encontrar. Sí se encontraron vacas con la enfermedad en Puebla, Durango y Valladolid (Michoacán), pero fueron descubrimientos esporádicos (Smith, "Balmis" 137-39).
} 
un costo monetario que no todos los pueblos se podían permitir y encontrar unos padres dispuestos a "prestar" a sus hijos para esto.

Una vez que se había conseguido el fluido en la ciudad, se vacunaba a los primeros niños, quienes tenían que volver algunos días más tarde para comprobar si habían aparecido erupciones y si se podía utilizar el pus para administrarlo al resto de los niños. Además de que en demasiadas ocasiones la vacuna no tenía los efectos deseados, una buena parte de los niños no regresaban a "devolver" parte del pus que se les había inoculado. En ocasiones el problema era conocer exactamente cuándo se produciría la deseada erupción, pues si era muy rápida, para cuando los niños eran citados el fluido ya se había secado:

Ha sido tan violenta dicha operación que ayer [día] 17, habiéndose vacunado el 13 ya había desecado el pus y otros están actualmente en disposición de modo que será preciso sucesivamente tener particular cuidado para que no se extinga por un leve descuido. [...] También será porque no hay en estos pueblos un facultativo examinado en cirugía que tuviese bajo su inspección a los subalternos que la propagasen y cuidase de que cada tres, seis o nueve días se extinga el pus o se pase de su madurez. (AHESLP, I 1810-1811.3, exp. 13)

Las primeras vacunaciones realizadas en San Luis fueron realizadas por los médicos Gutiérrez y Arboleya con fluido traído por ellos mismos. Desde 1810 hasta 1821 fueron constantes las peticiones de fluido por parte de los subdelegados al intendente y de éste al virrey. En 1810, las autoridades virreinales mandaron junto con varios ejemplares que enseñaban el modo de aplicar la vacuna, el preciado fluido, pero pronto se quedaron sin él (AHESLP, $I$ 1810-1811.3, exp. 14). En 1814, con la urgencia de que se estaba produciendo un nuevo brote epidémico se consiguió fluido en Querétaro, donde ya había llegado la epidemia y donde se había demostrado que la vacunación era el único remedio para evitar las muertes (AHESLP, I 1814.4, exp. 4 y 1816.1, exp. 3). A finales del año ya no había existencias, por lo que en 1815 se realizó un nuevo envío y al menos otros tres en 1816 (AHESLP, $I$ 1815.2, exp. 8 y 1816.1, exp. 3). En 1817 y 1818 hubo varias peticiones del pus, pero desde el virreinato se les respondió que intentaran conseguirlo en Zacatecas o en alguna ciudad más cercana para ver si de esta forma no se echaba a perder (AHESLP, I 1817.2, exp. 7 y 1818.2, exp. 4). En ninguna de éstas disponían de vacuna, así que no se recibió más fluido hasta 1819, año en que se consiguió por un particular; ese fluido se terminó para finales de año, por lo que al año siguiente llegó otra remesa que tampoco duró mucho (AHESLP, I 1820.9, exp. 6). 


\section{FRONTERAS}

de la fistoria

La dificultad para transportar y mantener el fluido fue un problema general. De hecho, la expedición de Balmis se organizó porque las autoridades españolas no encontraron otra forma de acercar el fluido vacuno hasta el continente americano. Las dos formas de transportarlo eran el virus seco en costras (en hilas de algodón, en lancetas o en vidrios cerrados) y el virus fresco (de brazo en brazo). Los estudios realizados en esos años mostraban que la eficacia era más alta cuando se elegía la segunda forma, pero no siempre se conseguía mantener el virus activo ${ }^{22}$. Estudios realizados por diferentes médicos tanto en Europa (Husson) como en América (Romay y Wattehouse) demostraron que el virus se perdía con temperaturas superiores a $\operatorname{los} 28^{\circ} \mathrm{C}$ o $30^{\circ} \mathrm{C}$, y estas temperaturas se superaban durante la mayor parte del año en la intendencia $\operatorname{potosina}^{23}$.

Otros lugares, por ejemplo Guatemala, Oaxaca o Venezuela, también tuvieron que lidiar con esta falta de fluido (Smith, "Balmis" 136). El problema de la pérdida del preservativo y la dificultad para reponerlo no se solucionaron en mucho tiempo. Pronto se descubrió que se conseguían mejores resultados con fluido tomado directamente del animal, por lo que se organizaban viajes con una ternera portadora del virus. Posteriormente, se utilizó la glicerina como bactericida y, finalmente, la liofilización, que sirvió de base tecnológica para la conservación durante largo tiempo en climas cálidos, pero esto no se logró hasta bien entrado el siglo XX (Nájera 226-27).

Un segundo problema es que mucha gente no sólo dudaba de que la vacuna fuera benéfica, sino también de que no fuera peligrosa. Esto se debía a que la mayor parte de la población no distinguía entre los riesgos de la inoculación (como hemos visto, eran bastante grandes) y los de la vacunación, para ellos ambos procedimientos eran lo mismo. Incluso los oficiales encargados de certificar los procedimientos erraban con los nombres ${ }^{24}$.

Para acabar con las reticencias de la población y que aceptaran la vacuna se recurrió a los obispos y curas párrocos; éstos debían utilizar los sermones de las

\footnotetext{
${ }^{22}$ En 1800, el médico Husson escribió un artículo en el Diario de París donde expuso las diferentes formas de transportar la vacuna y sus experimentos para comprobar cuál era el más efectivo (Nájera 216).

${ }^{23}$ Los experimentos que Waterhouse realizó en Boston durante junio y julio anotando las temperaturas de cada día y los efectos de la vacuna fueron publicados en 1801 con el título: $O n$ the Difficulty of Perserving the Vaccine Virus on Threads or Glass in Very Hot Weather (Nájera 222-23).

${ }^{24}$ Hemos visto en la nota 16 cómo hasta los propios médicos confundían los términos.
} 
misas dominicales para exaltar las bondades del nuevo remedio y para convencer a los padres que llevaran a sus hijos a vacunar en los días indicados. La labor de los clérigos no se limitó a un "trabajo propagandístico", sino que también tomaron parte activa en la administración de la vacuna. En muchas ocasiones los atrios de la Iglesia eran los lugares elegidos como "centro de vacunación"; en otras, el cura acompañaba a los niños elegidos para traer la vacuna de la capital, y a veces eran ellos los que preparaban la llegada del fluido $^{25}$. Las autoridades estaban convencidas de que la presencia de un párroco en el que confiaran sus feligreses era la mayor garantía del éxito:

Estos habitantes, principalmente los indios y gente plebeya han resistido siempre la vacunación en sus hijos [...] para hacerlos entender es necesario la influencia del R.P. cura fray Vicente de Vitoria quien con su agradable modo consiguió en la villa de Tula que todos se vacunaran con tan admirables efectos que se libertaron todos a excepción de muy pocos del último contagio de viruelas [...]. (AHESLP, $I$ 1819.1, exp. 10).

A pesar de lo que acabamos de decir, el papel del clero en la vacunación no tuvo la misma importancia en todas las provincias y virreinatos americanos. Así, mientras que en la intendencia de Guanajuato su intervención fue mínima, en lugares como Venezuela los estudios preliminares indican que tuvieron una influencia decisiva (Esparza y Colmenares 112-13; Thompson 453). Es muy posible que el tipo de relación existente entre el clero y las autoridades civiles marcara el papel de los curas párrocos y religiosos en esta labor. Es conocido que la actitud del intendente Riaño, tanto en Guanajuato como anteriormente en Michoacán, fue de abierta hostilidad hacia el clero de su jurisdicción mientras que, por el contrario, en San Luis Potosí las relaciones fueron mucho más cordiales (Brading; Franco Cáceres).

La ajustada economía de la mayoría de las poblaciones fue otra de las dificultades para la vacunación. Ya hemos comentado que ni siquiera la capital consiguió abrir una casa de vacunación a pesar de que estaba previsto en el reglamento que trajo consigo el médico Gutiérrez como responsable de la expedición en San Luis y que volvió a enviar el propio Balmis en 1810. Este problema de falta de presupuesto era más grave en los partidos del interior, que tenían una población y unos recursos mucho más limitados. Varios subdelegados se quejaron del costo que suponía mandar hasta la capital de la

\footnotetext{
${ }^{25}$ El papel que desempeñaron los curas en la generalización de la vacuna es mencionado en prácticamente todos los documentos consultados que se encuentran citados en las notas precedentes.
} 


\section{FRONTERAS}

de la historia

intendencia a dos o tres niños con un responsable con el fin de que consiguieran el fluido ${ }^{26}$. El caso extremo fue el de Salinas del Peñón Blanco; su subdelegado fue el único que aludió a la falta de dinero como único motivo para no haberse realizado ninguna vacunación: "Es imposible que los vecinos puedan costear esto por su cuenta que apenas tienen para comer (a veces ni siquiera), un real o dos que es lo que diariamente consiguen no basta ni para la precisa manutención de casa individuo" (AHESLP, I 1810-1811.3, exp. 5).

La última gran dificultad, muy unida a la de la falta de dinero, es la falta de médicos preparados para realizar la operación. A pesar de que los responsables de la expedición afirmaban que se trataba de una operación sencilla, lo cierto es que no en todos los pueblos había personas capaces de realizarla y menos sin recibir ningún dinero a cambio. El número de médicos y cirujanos era muy escaso en la intendencia, por lo que las autoridades decidieron que debían ser los barberos de las distintas localidades los que aprendieran la técnica y realizaran las operaciones.

La documentación consultada nos habla únicamente de ocho médicos que colaboraban en la generalización de la vacuna por todo el territorio potosino: José Camaño, Antonio Cervera, Pedro Puglia, Miguel María Jiménez, Anastasio Ruiz de Bustamante, Manuel Altamirano, Mariano Gutiérrez e Ignacio López Portillo. La mayoría de ellos colaboraron con la vacunación esporádicamente y sobre todo en la capital de la intendencia: Camaño y Cervera, durante los primeros meses de la campaña, en 1805; Anastasio Ruiz de Bustamante, durante 1810, Manuel Altamirano y Mariano Gutiérrez, de 1815 a 1819. Fuera de la capital encontramos a Pedro Puglia durante algunos meses de 1810 y a Miguel María Jiménez, que vacunó en Real de Catorce durante 1814. Finalmente, Ignacio López Portillo vacunó en Valle del Maíz y otras localidades de la Huasteca durante varios meses de 1819. Real de Catorce se convirtió durante estos años en el principal centro minero de la provincia potosina, lo cual ayudó a que la población contara con un médico y que se hiciera al menos una campaña de vacunación. La necesidad de mantener la mano de obra que trabajaba en la extracción del metal debió de influir en ello.

\footnotetext{
${ }^{26}$ La mayoría de los subdelegados hicieron una colecta entre la población de sus jurisdicciones, pero lo recogido apenas solía bastar para un primer viaje por fluido, así que cuando éste se terminaba o si se había estropeado y no servía para vacunar, no hacían una segunda recolección: "[...] para este segundo viaje no se volvió a molestar a los vecinos con nueva contribución pues se acordó entre el expresado D. Andrés Girón y yo no gravar a nadie en esa parte" (AHESLP, I 1810-1811.3, exp. 15).
} 
Los cirujanos, sangradores y barberos fueron los que practicaron mayor número de vacunaciones. La documentación nos indica que, al menos en la capital, los médicos dirigieron la vacunación, pero contaron con los cirujanos para realizar las operaciones. En las primeras inoculaciones que se realizaron en enero de 1805, pocos días después de la marcha del médico Gutiérrez y de la expedición, colaboraron tanto los dos médicos como los dos cirujanos que formaban parte de la Junta de Vacunación, pero ya en febrero son los dos cirujanos los que se responsabilizaron de la campaña ${ }^{27}$. En 1810, el médico Anastasio Ruiz de Bustamante realizó un ensayo experimental sobre la vacuna y las causas de su éxito o fracaso, pero el que hizo las inoculaciones sobre las que se sacaron las conclusiones fue el cirujano Francisco Guardiola (AHESLP, I 1810-1811.3, exp. 2) ${ }^{28}$. En la campaña de 1815-1816, junto con los médicos Altamirano y Gutiérrez participó el cirujano Blas de Azpilicueta.

En las distintas subdelegaciones hubo más cirujanos, barberos y sangradores que médicos, aunque entre estos últimos destaca Ignacio López Portillo, quien, junto con el sangrador Pío Quinto Burgos, se encargó de la vacunación de la zona Huasteca comenzado por Ciudad del Maíz. En Real del Catorce los médicos Pedro Puglia y, especialmente, Miguel María Jiménez se encargaron sobre todo de enseñar el método a los barberos: "Con este fin enseñé a varios barberos el sencillísimo método de vacunar" (AHESLP, I 1810-1811.3, exp. 13). En la práctica se demostró que el método no era tan sencillo y que los "pseudodoctores" que vivían en los pueblos no estaban preparados para realizar estas operaciones (AHESLP, I 1810-1811.3, exp. 5).

El estudio de Thompson sobre la vacunación en la intendencia de Guanajuato nos muestra que los problemas que allí se dieron fueron muy parecidos a los de San Luis Potosí: dificultad para conseguir y conservar el fluido vacuno, reticencias de muchos padres a vacunar a sus hijos, escasez de personal capacitado para realizar la operación y un presupuesto demasiado ajustado para

\footnotetext{
${ }^{27}$ En enero de 1804 vacunaron los cuatro facultativos: los médicos Camaño y Cervera, 645 y 276 personas respectivamente; y Barrenechea y Guardiola, 327. Pero en febrero la Junta decidió pagar a Barrenechea y a su ayudante Guardiola 400 y 200 pesos, respectivamente, porque se habían comprometido a vacunar regularmente a toda la población en su propia casa (AHESLP, I 1804.1, exp. 8).

28 "Estado histórico-práctico de los principales resultados y fenómenos que han ofrecido a la observación del médico de la ciudad D. Anastasio Ruiz de Bustamante los ensayos de vacunación que por orden del señor intendente D. Manuel Jacinto de Acevedo ha practicado el cirujano Francisco Guardiola con el objeto de examinar la calidad del pus que a solicitud de éste último facultativo ha sido transportado en hilas desde Valladolid."
} 


\section{FRONTERAS}

de la fistoria

poder afrontar la misión. Esto provocó que en la capital de Guanajuato se consiguiera un relativo éxito en la vacunación, pero no en los distritos rurales (Thompson 453-54). Para haber llevado hasta allí la vacuna habría sido necesario crear una infraestructura sanitaria como la que trató de instaurar Balmis en los artículos de su Junta de Vacunación y conseguir el fluido del ganado vacuno de la jurisdicción.

\section{Conclusiones}

La expedición de Balmis de 1804 - realizada dentro del contexto ilustrado y en un momento de gran auge científico y técnico- fue el primer intento de generalizar la vacuna contra la viruela entre toda la población de la América hispana y se prolongó hasta el fin de la época colonial. El objetivo de esta misión no fue sólo aplicar preservativo al mayor número posible de niños, sino preparar y organizar las condiciones necesarias para que las autoridades locales y regionales establecieran una vacunación sistemática que asegurara que todo niño nacido a partir de entonces fuera inmunizado. Para ello enseñaron la técnica al personal sanitario existente y ordenaron la fundación de una junta de vacunación en cada una de las jurisdicciones, la cual debía velar por la buena organización y desarrollo del proyecto. Así pues, se trató de la primera campaña sanitaria global que trató de erradicar una enfermedad aplicando una política sanitaria y de salud pública.

En la provincia potosina, esta Junta se fundó a las pocas semanas de la visita del médico Gutiérrez, uno de los ayudantes de Balmis, y vacunó durante varias semanas a los niños más pequeños de la ciudad y sus barrios circundantes. En un primer momento dos médicos acompañados de dos enfermeros vacunaron en sus propias casas cada diez días a toda la población que deseaba recibir el preservativo, pero la falta de fluido vacuno y de fondos con los cuales pagar a los médicos y enfermeros hizo que a partir de marzo de 1805 las vacunaciones fueran esporádicas: en 1806, cuando visita la ciudad el médico Arboleya; en 1814, cuando el pus llega desde Querétaro, y 1819, cuando llega desde México.

En las jurisdicciones rurales los problemas fueron más grandes, y los resultados, más modestos. En ellas era más difícil conseguir el fluido porque debían mandar a la ciudad de San Luis Potosí a varios niños con un responsable con el fin de que con la misma técnica del brazo a brazo llegara activo hasta la población. Esto implicaba que hubiera padres dispuestos a permitir que sus niños hicieran de portadores del pus, pagar el viaje de los niños y el responsable y conseguir que el virus no se hubiera perdido en el camino. A esto había que añadir la falta de personal sanitario preparado para practicar la pequeña 
operación y convencer a los padres de que la vacuna era un verdadero remedio y no una enfermedad voluntaria, como la llamaban muchos de ellos.

A pesar del esfuerzo de las autoridades civiles y religiosas, el objetivo de erradicar la viruela no se consiguió hasta bien entrado el siglo XX; la buena voluntad no fue suficiente. Los escasos recursos económicos, los insuficientes conocimientos técnicos y la falta de administración y logística sanitaria que abarcara todo el territorio impidieron lograr el objetivo, pero el primer paso se había dado. El ejemplo de la campaña de Balmis y los esfuerzos posteriores en las distintas jurisdicciones mostraron a las autoridades y a los profesionales sanitarios que era posible erradicar una enfermedad por medio de la prevención, pero también que para lograrlo había que crear una administración sanitaria que fuera capaz de llegar a todo el territorio y sus habitantes y dedicar una partida presupuestaria acorde con la magnitud del proyecto.

\section{Bibliografía}

\section{Fuentes primarias}

Archivo Histórico del Estado de San Luis Potosí, San Luis Potosí, México (AHESLP).

Intendencia (I) 1792-1795, 1804.1, 1810-1811.3, 1814.4, 1815.2, $1816.1,1817.2,1818.2,1819.1$ y 1820.9 .

Biblioteca Rafael Montejano y Aguiñaga, San Luis Potosí, México (BRMA).

San Luis Potosí (SLP). Microfilme rollo 41.

\section{Fuentes secundarias}

Albiñana y Sanz, J. M. "El Dr. Balmis y su obra”. El Siglo Médico 66 (1919): 125-29.

Anes y Álvarez de Castrillón, Gonzalo. La Corona y la América del Siglo de las Luces. Madrid: Marcial Pons; Asociación Francisco López de Gomara, 1994. 


\section{FRONTERAS}

de la historia

Vol. $12 / 2007$

Archila, R. "La expedición de Balmis en Venezuela". IV Congreso Panamericano de Historia de la Medicina, Caracas. 1969.

Balaguer Perigüell, Emilio. Balmis o l'esperit de la Illustració en la medicina espanyola. Valencia: Generalitat Valenciana, 1996.

Ballester Añón, María Rosa. "Repercusiones y significado de la Real Expedición Filantrópica de la Vacuna". La Ilustración Española. Eds. A. Alberola y E. Laparra. Madrid: Instituto Gil Albert, 1986. 35-44.

Balmis, Francisco Javier. Prólogo y traducción castellana del 'Tratado histórico y práctico de la vacuna' de J. L. Moreau. Intr. de Emili Balague i Perigüell [1803]. Valencia: Alfons el Magnànim, 1987.

- Demostración de la eficaces virtudes nuevamente descubiertas en las raíces de dos plantas de Nueva España, especies de Ágave y de Begonia, para la curación del vicio venéreo y escrofuloso, y de otras graves enfermedades que resisten al uso del Mercurio, y demás remedios conocidos. Madrid: s. e. 1794.

- y Berenguer. Ueber die amerikanischen pflanzen Agave und Begonia als zwei neuentdeckte specifische Mittel gegen die dustsenche, Scrophel [...] aus dem Spanischen ins Italienischen uns aus diesen ins Deutsche übersetzt, nebt Anmerkugen, von Friederich Luddwig Kreysig. Leipzig: s. e. 1797.

Barona Vilar, José Luis. "Francisco Javier Balmis y la Real Expedición Filantrópica de la Vacuna (1803-1806)". Eidon 7 (2001).

Baxby, D. “Edward Jenner's Inquiry: a bicentenary análisis". Vaccine 17.4 (1999): 301-307.

Brading, David A. Una Iglesia asediada: el obispado de Michoacán, 17491810. México: Fondo de Cultura Económica, 1994.

Burkholder, Mark A. y D. S. Chandler. De la impotencia a la autoridad. La Corona española y las audiencias en América (1687-1808). México: Fondo de Cultura Económica, 1984. 
Bustamante, Miguel E. "La Viruela en México, desde su origen hasta su erradicación". Ensayos sobre la historia de las epidemias en México. Comps. Enrique Florescano y Elsa Malvado. México: IMSS, 1982.

Calatayud Arinero, M. A. Catálogo de las expediciones y viajes científicos españoles. Madrid: Consejo Superior de Investigaciones Científicas, 1984.

Calleja Folguera, María del Carmen. La reforma sanitaria en la España ilustrada. Madrid: Universidad Complutense de Madrid, 1988.

Castillo y Romper, J. Real expedición filantrópica para proteger en vacuna en América y Asia (1803) y progresos de la vacunación en nuestra península en los primeros años que siguieron al descubrimiento de Jenner. Madrid: Rojas, 1912.

Clavijo y Clavijo, S. "Prioridad de los médicos de la Armada en la introducción y propagación de la vacuna jenneriana en la América Española". El Siglo Médico 96 (1935).

Commons, Aurea. Las intendencias de Nueva España. México: Universidad Nacional Autónoma de México, 1993.

Cook, S. F. "Francisco Javier Balmis and the Introduction of Vaccinations to Latin America". Bulletin of the History of Medicine 23 (1949): 312-14.

Díaz de Yraola, E. La vuelta al mundo de la expedición de la vacuna. Sevilla: Escuela de Estudios Hispanoamericanos, 1956.

Esparza, José. "La introducción de la viruela en América: Epidemias en América Latina durante el siglo XVI". Tierra Firme 18 (2000): 527-61.

Esparza, José y Germán Yepes Colmenares, "Viruela en la Venezuela colonial: epidemias, variolización y vacunación". La Real Expedición Filantrópica de la Vacuna. Doscientos años de lucha contra la viruela. Eds. Susana Ramírez et al. Madrid: Consejo Superior de Investigaciones Científicas, 2004.

Florescano, Enrique e Isabel Gil. Descripciones económicas generales de Nueva España (1784-1817). México: Instituto Nacional de Antropología e Historia, 1973. 


\section{FRONTERAS}

de la historia

Vol. $12 / 2007$

Franco Cáceres, Iván. La intendencia de Valladolid de Michoacán: 1786-1809. México: Fondo de Cultura Económica, 2001.

Gibson, C. The Aztecs under Spanish Rule. Stanford: Stanford University Press, 1964.

Gimeno Caballas, A. "La expedición de Balmis". El Siglo Médico 71 (1923): 453-57.

Gorráiz Beaumonte, V. F. Juicio o dictamen sobre el proceso de la inoculación presentado al Tribunal de los sabios para que la juzguen, por el doctor en medicina D. Francisco Salvá y Campillo. Pamplona: Imprenta de Joseph Longas, 1785.

Guerra, Francisco. Epidemiología americana y filipina, 1492-1898. Madrid: Ministerio de Sanidad y Consumo, 1999.

Hamnet, Bryan R. Raices de la insurgencia en México. Historia regional 17501824. México: Fondo de Cultura Económica 1990.

Hopkins, D. R. Princes and Peasants: Smallpox in History. Chicago: Chicago University Press, 1983.

Irisarri, Ana. "Política reformista y modernidad en la provincia de San Luis Potosí durante la Intendencia”. México: Instituto Nacional de Antropología e Historia, 2007. En prensa.

Izaguirre Torres, J. La viruela en la población novohispana de San Luis Potosí. Más de 9.000 muertes en una epidemia, 1798-1799. San Luis Potosí: El Colegio de San Luis Potosí, 2003.

López de Gómara, Francisco. Conquista de México. México: Orbis, 1985. Vol, 2 de Historia de las Indias. 2 vols. 1985.

Mariscal, N. "Prelusión histórica sobre la vacuna. Homenaje a Jenner”. El Siglo Médico 71 (1923): 329-33.

Miller, G. The Adoption of Inoculation for Smallpox in England and France. Philadelphia: University of Pennsylvania Press, 1957. 
Monroy, Isabel. Pueblos, misiones y presidios de la Intendencia de San Luis Potosí. San Luis Potosí, México: Archivo Histórico del Estado, 1991.

—. Breve historia de San Luis Potosí. México: Fondo de Cultura Económica, 1997.

Montejano y Aguiñaga, Rafael. Calles y callejones del viejo San Luis. San Luis Potosí, México: Montejano y Aguiñaga, 1992.

Morales Moya, A. "Política social”. Historia de España. Vol. 31. Dir. Ramón Menéndez Pidal. Madrid: Espasa-Calpe, 1989.

Moreno Caballero, E. Sesión apologética dedicada al Dr. D. Francisco Xavier del Balmis y Berenguer. Valencia: Instituto Médico Valenciano, 1885.

Moss, B. "Poxviruses: The Viruses and Their Replication". Field Virology. Eds. D. M. Knipe, et al. Philadelphia: Lippicott Raven, 1996.

Moulin, A. M. y P. Chauvin. Lady Mary Montagu. L'Islam au peril de femmes. París: s. e., 1987.

Nájera, R. "Dos momentos en la historia de la viruela". La Real Expedición Filantrópica de la Vacuna. Doscientos años de lucha contra la viruela. Eds. Susana Ramírez et al. Madrid: Consejo Superior de Investigaciones Científicas, 2004.

Navarro, Luis. Las reformas borbónicas en América. El plan de Intendencias y su aplicación. Sevilla: Consejo Superior de Investigaciones Científicas, 1995.

Nieto Antúnez, P. La rectora de la casa de expósitos de La Coruña, excepcional y olvidada enfermera en la expedición Balmis. La Coruña: Instituto José Cornide de Estudios Coruñeses, 1981.

O’Gormann, Edmundo. Historia de las divisiones territoriales de México. México: Porrúa, 1973.

Olagüe de Ros, Guillermo. "La introducción de la vacunación jenneriana en España (1799-1805)". Malaltia i Cultura. Valencia: Universitat de Valencia; Seminari d'Estudis sobre la Ciencia, 1995. 251-73. 


\section{FRONTERAS}

de la historia

Vol.12 / 2007

Ovieta, A. "Historia de la vacuna". El Siglo Médico 7 (1860).

Páez, Eduardo. "El origen de la vacuna de la viruela". La Real Expedición Filantrópica de la Vacuna. Doscientos años de lucha contra la viruela. Eds. Susana Ramírez et al. Madrid: Consejo Superior de Investigaciones Científicas, 2004.

Pietschmann, Horst. Las reformas borbónicas y el sistema de intendencias en Nueva España. México: Fondo de Cultura Económica, 1972.

Priestley, Herbert Ingram. Las reformas de José de Gálvez en Nueva España. México: s. e., 1983.

Ramírez Martín, Susana María. La mayor hazaña médica de la Colonia: la Real Expedición Filantrópica de la Vacuna en la Real Audiencia de Quito. Quito: Abya-Yala, 1999.

-. La salud del Imperio: la Real Expedición Filantrópica de la Vacuna. Madrid: Doce Calles; Fundación Jorge Juan, 2002.

— et al., eds. La Real Expedición Filantrópica de la Vacuna. Doscientos años de lucha contra la viruela. Madrid: Centro Superior de Investigaciones Científicas, 2004.

Rees Jones, Ricardo. El despotismo ilustrado y los intendentes de la Nueva España. México: Universidad Nacional Autónoma de México, 1979.

Regli Fernández, E. y F. Palma Alonso. "Archivo de Indias de Sevilla. Introducción de la vacuna en América". Trabajos de la Cátedra de Historia Crítica de la Medicina. t. 7. Madrid: s. e., 1936.

Rico Avello, C. La expedición de Balmis. XV Congreso Internacional de Historia de la Medicina. Alcalá; Madrid: Instituto Arnaldo de Vilanova de Historia de la Medicina, 1958.

Rigau-Pérez, José G. "La difusión en Hispanoamérica de las primeras publicaciones españolas sobre la vacuna (1799-1804)". Asclepio 44 (1992): 165-79.

—. "La introducción de la vacuna de viruela en Puerto Rico, 1803-1804". La Real Expedición Filantrópica de la Vacuna. Doscientos años de lucha 
contra la viruela. Eds. Susana Ramírez et al. Madrid: Consejo Superior de Investigaciones Científicas, 2004.

Rodríguez de Romo A. C., "Inoculación en la epidemia de viruela de 1797 en México: ¿Mito o solución real?”. Antilla: Revista Española de Historia de las Ciencias de la Naturaleza y de la Tecnología 3 (1997): 1-17.

Ruiz Moreno, Aníbal. Introducción de la vacuna en América: (Expedición de Balmis). Buenos Aires: Cátedra de Historia de la Medicina, 1956.

Rumeu de Armas, A. La inoculación y la vacuna antivariólica en España. Valencia: s. e., 1940.

Sahagún, Bernardino de. "La conquista de Nueva España". Historia General de las Cosas de Nueva España. T. 4. Libro XII. México: Porrúa, 1969.

Santamaría, E. "Las salas de vacunación en los hospitales peninsulares a principios del siglo XIX". Dynamis 10 (1990): 303-322.

Sarrailh, Jean. La España Ilustrada de la segunda mitad del siglo XVIII. México: Fondo de Cultura Económica, 1956.

Smith, Michael. "The Real Expedición Marítima de la Vacuna". New Spain and Guatemala. The American Philosophical Society. Philadelphia: s. e., 1974.

-. "Balmis en la Nueva España: Cuba, Guatemala y México". La Real Expedición Filantrópica de la Vacuna. Doscientos años de lucha contra la viruela. Eds. Susana Ramírez et al. Madrid: Consejo Superior de Investigaciones Científicas, 2004.

Swann, M. M. Tierra adentro: Settlement and Society in Colonial Durango. Bouler: Westview Press, 1982. 154-69.

Thompson, Angela T. "To Save the Children: Smallpox, Inoculation, Vaccination, and Public Health in Guanajuato, Mexico, 1797-1840". The Americas 49.4 (1993) 431-55.

Vázquez, Josefina Zoraida, coord. Interpretaciones del siglo XVIII mexicano. El impacto de las reformas. México: Nueva Imagen, 1992. 


\section{FRONTERAS}

de la fistoria

Vol.12 / 2007

Watts, Sheldom. Epidemias y poder. Historia, enfermedad, imperialismo. Barcelona: Andrés Bello, 2000.

Fecha de recepción: 2 de marzo de 2007.

Fecha de aceptación: 30 de julio de 2007. 